\title{
Wood Knots Influence the Modulus of Elasticity and Resistance to Compression
}

\author{
Maria Fernanda Vieira Rocha ${ }^{1}$, Lívia Ribeiro Costa ${ }^{1}$, \\ Luciano Junqueira Costa ${ }^{2}$, Ana Clara Caxito de Araújo ${ }^{1}$, \\ Bruno Charles Dias Soares ${ }^{1}$, Paulo Ricardo Gherardi Hein ${ }^{1}$ \\ ${ }^{1}$ Universidade Federal de Lavras - UFLA, Lavras/MG, Brasil \\ ${ }^{2}$ Universidade Federal de Viçosa - UFV, Viçosa/MG, Brasil
}

\begin{abstract}
The objective of this study was to establish the correlation between the size of the wood knots and the modulus of elasticity (MOE) and the compressive strength (Fc) in Eucalyptus wood. 156 Eucalyptus urophylla samples with knots were separated into 3 classes (small, medium and large knots), and samples were selected from the same tree and submitted to the parallel fiber compression test for MOE and $\mathrm{Fc}$ determination. There was a significant difference between the MOE and $\mathrm{Fc}$ of the smaller knot class (Class 1) and the other classes with larger knots (Classes 2 and 3). In general, the larger the knot, the greater the difference between the MOE and Fc. Wood with small knots $\left(8.31 \mathrm{~mm}^{2}\right)$ presents stiffness and strength statistically equal to wood free of defects. Eucalyptus wood stiffness is more sensitive to the presence of knots than the strength when compared to clear wood samples.
\end{abstract}

Keywords: strength, stiffness, Eucalyptus, wood structure. 


\section{INTRODUCTION}

The occurrence of knots in the wood are anatomical defects that damage or render wood useless for certain applications. Knots are the embedded basal portion of a branch in the trunk that cause deviations in the woody tissue, as well as difficulty during processing, loss of mechanical strength in the workpiece and reduced wood quality (Krutul et al., 2013; Vek et al., 2014).

The presence of knots causes deviations in the fiber direction affecting the anatomical structure of the wood. The regions around the knots present inclined fibers or some type of deviation and have lower stiffness and strength against force applied in the direction parallel to the length than in comparison with areas of straight and oriented fibers (Košíková, 2009). The effect of knots on strength can be influenced by factors such as: cross section dimensions occupied by the knot, knot type, distribution location and distribution of the stresses present in the timber. (Gupta et al., 2004; Nagai et al., 2010).

For structural usage, it is desirable to use clear wood, or any other wood free of defects that may affect its mechanical strength. Mechanical resistance can be evaluated by several specific estimators. The estimator presented and recommended by ASTM D -143 (ASTM, 1997) suggests that for evaluation of the mechanical properties by means of parallel compression tests for the wood fibers, the specimens should not present structural defects such as knots or holes.
Due to this requirement of the standard, it is difficult to obtain wood samples totally free of defects, and there may be a great deal of wasted material considered unsuitable for mechanical testing. Therefore, it is necessary to understand how the dimensions of the wood knot interfere in the wood's mechanical properties, especially the stiffness and compression strength.

Hence, the objective of this study was to evaluate the effect of knot size on stiffness and strength of Eucalyptus wood.

\section{MATERIAL AND METHODS}

12-year-old Eucalyptus urophylla clones from commercial plantations located in Brasília de Minas, Minas Gerais ( $16^{\circ} 12^{\prime} 30$ “South, $44^{\circ} 25^{\prime} 35^{\prime}$ ” West) were used in this study. Wooden strips were removed from central planks of 32 trees (Figure 1). Wood samples with knots were removed from the strips. The knots were classified into three (3) classes according to their occupied area: small knots, up to $8.31 \mathrm{~mm}^{2}$ (Class 1 ), medium knots, from 8.31 to $33.43 \mathrm{~mm}^{2}$ (Class 2) and large knots, from 33.44 to $105.36 \mathrm{~mm}^{2}$ (Class 3), according to Figure 2.

The 156 samples with nominal dimensions of $100 \times 25 \times 25 \mathrm{~mm}$ were used for parallel fiber compression testing to determine the modulus of elasticity (MOE) and wood strength $(\mathrm{Fc})$ according to procedure D 143-94 (ASTM, 1997). The samples had $12 \%$ of moisture content and showed well defined

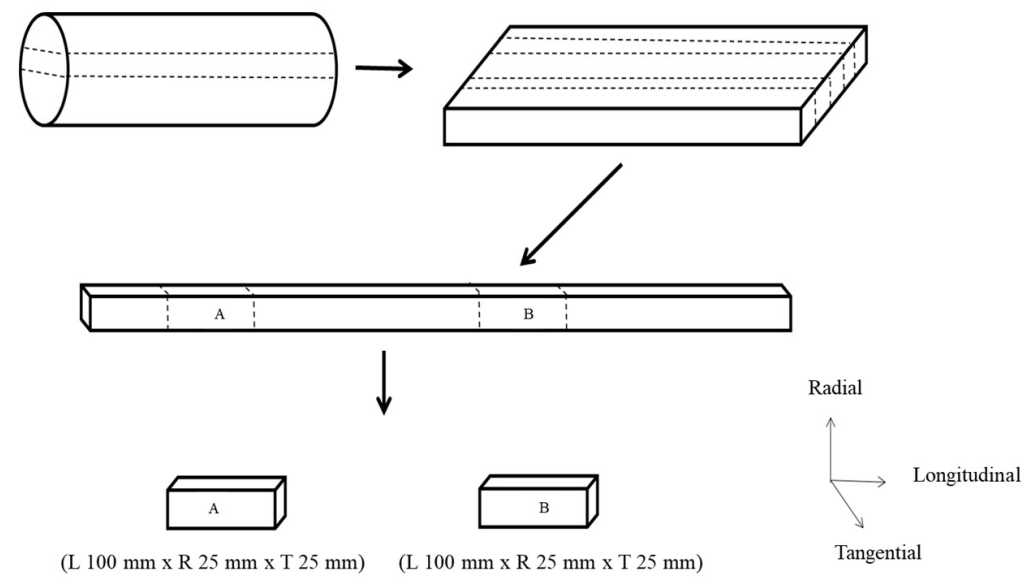

Figure 1. Methodology for sampling and obtaining test samples. A: clear wood; B: wood with knot. 


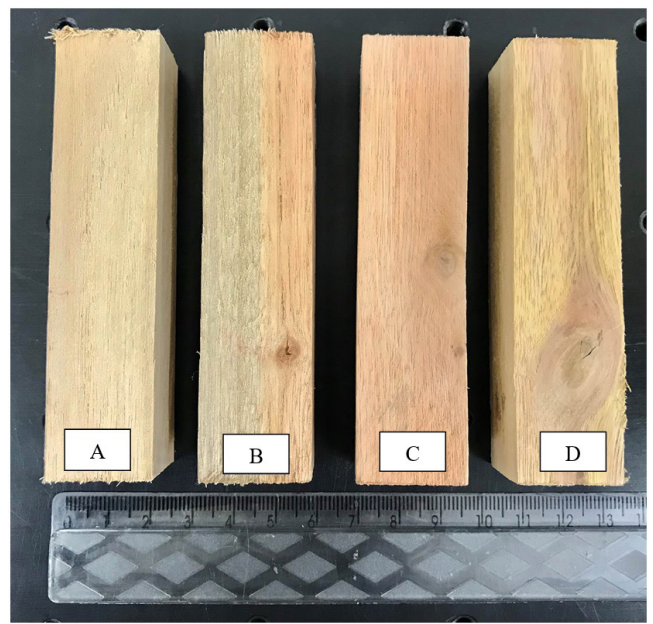

Figure 2. Samples in different classes of knots. A: clear wood; B: class 1; C: class 2; D: class 3.

tangential and radial faces. The tests were carried out on a Universal Testing Machine (model EMIC DL - $30 \mathrm{kN}$ ).

The data of the evaluated parameters were submitted to analysis of variance (ANOVA), applying the $\mathrm{F}$ test at $5 \%$ significance. Means were subsequently compared by Tukey test at $10 \%$ significance. Regression analysis was used to detect the correlation between the factors.

\section{RESULTS AND DISCUSSION}

The average values of the modulus of elasticity (MOE) and wood strength of clear wood samples (without knots) compared to wood samples with knots, within the different size classes can be seen in Figure 3 .

Class 1 presented an average MOE for the clear wood of $7.649 \mathrm{MPa}$, and for wood with knots in this class, $7.144 \mathrm{MPa}$ (Figure 3). In class 2 and 3, the average MOE was 6,585.7 MPa and 7,276.1 MPa for clear wood samples, and an average MOE of 5,583 MPa and 5,588 MPa for the wood with knots, respectively.

Figure 3 (B) demonstrates that the Class 1 samples presented average strength for the clear wood of 53.2 $\mathrm{MPa}$, and for the wood with knots belonging to this class of $46.9 \mathrm{MPa}$. In Class 2 and 3, the average strength of clear wood was $47.7 \mathrm{MPa}$ and $50.9 \mathrm{MPa}$, and for the wood with the knots it was $38.8 \mathrm{MPa}$ and $39.6 \mathrm{MPa}$, respectively.

There is clearly a direct relationship between the MOE values and the size of the knots present in the
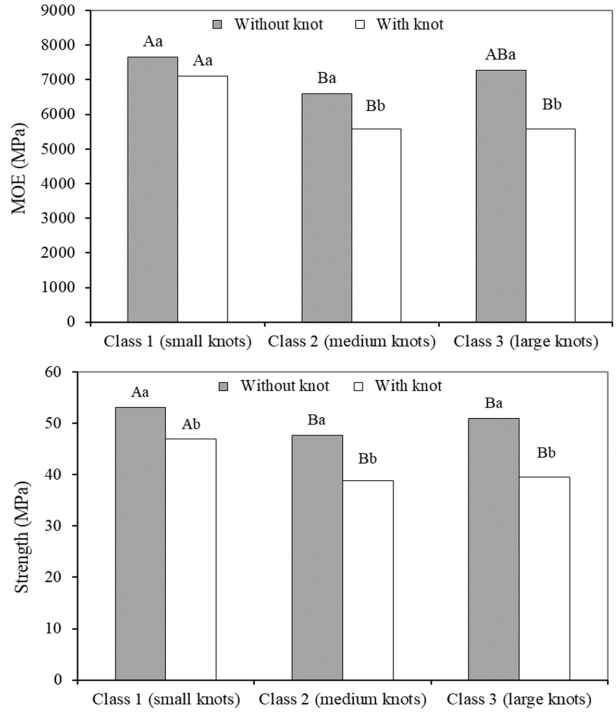

Figure 3. Modulus of elasticity (A) and compressive strength (B) of the wood samples without knot and within the different knot size classes. Means followed by upper and lower-case letters between presence and/or absence of knots do not differ from one another at the $10 \%$ level of significance by Tukey test.

analyzed parts. The higher the knot in the wood, the lower the MOE values obtained, as well as the greater the amplitude of variation, meaning $6.26 \%$ for Class 1 , $15.22 \%$ for Class 2 and $23.20 \%$ for Class 3. According to Koman et al. (2013), the increase in the proportions of knot areas results in a significant decrease of the modulus of elasticity (MOE), since the structure of the knots differs from that of normal wood.

Similar to that observed for the modulus of elasticity, the mechanical strength of the wood, reduced significantly with the presence of knots in the wood. Class 1 showed a reduction of $11.8 \%$ in the wood strength parallel to the fibers. For Classes 2 and 3, a reduction of $18.7 \%$ and $22.2 \%$, respectively, was observed in the mechanical strength of the wood.

Among the classes, Class 1 was different from the others (2 and 3), for both MOE and wood strength. Between presence and absence of knots, only Class 1 showed no significant difference for the MOE, unlike Classes 2 and 3 (medium and large knot classes, respectively).

According to Green et al. (1999) the reduction of the mechanical characteristics is approximately 
proportional to the size of the knot. The authors also mention that the study of this defect is important in the determination of wood quality, especially for structural usage.

The reduction of the mechanical resistance occurs due to the change of the continuity and direction of the fibers around the knot, or in other words, due to the deviation of the grain that occurs around the knot (Vek et al., 2014; Oh et al., 2010). Burger \& Richter (1991) state that in the case of compressive stress parallel to the fibers, the wood will be unstable due to the irregular grain near the knot.

According to Green et al. (1999), the influence of knots depends on their size, location, shape and stability, attendant local slope of grain and type of stress to which the wood member is subjected. Most of the mechanical properties are lower in sections containing knots than in clear straight-grained wood, because the clear wood is displaced by the knot, then the fibers around the knot are distorted resulting in cross grain and, the discontinuity of wood fiber leads to stress concentration.

The effect of a knot on the mechanical strength of the wood depends on the proportion of wood occupied by the knot, number of knots, nature, size and distribution of the knot, both along the length of a piece of wood and throughout its section (Hossein et al., 2011; Zhou et al., 2016).

According to Vital (2008), deviation in the orientation of the woody cells of the trunk in the region of the knot can restrict the use of the wood for certain specific purposes or products or make its use unfeasible, thus reducing the quality of the wood, mainly for structural and furniture usage.

Figure 4 shows the correlation between the modulus of elasticity (MOE) of the knotted wood, within the different size classes, with the MOE of the wood without knots (clear wood).

It can be observed that for the three classes of knot size evaluated, low coefficients of determination were obtained, showing that the relationship between the MOE of the clear wood and the MOE of the wood with knots is low, presenting $\mathrm{R}^{2}$ values of $0.309,0.312$ and 0.280 for Classes 1, 2 and 3 respectively. The larger the knot in the wood, the smaller the MOE ratio of this wood compared to the MOE of the wood without knots.
Some studies have shown that the presence of knots has a direct influence on wood strength (Grant et al., 1984; Xu, 2002; Gupta et al., 2004). Grant et al. (1984) found that MOE and strength values decreased with increasing knot size. Xu (2002) showed that the knots have a negative influence on the MOE, even if the wood with knots is apparently more rigid. Gupta et al. (2004) found no significant difference in strength between wood with knots and clear wood of the Douglas-fir tree.

Figure 5 shows the correlation between the resistance of the knotted wood and the strength of the wood with knots, within the different size classes.

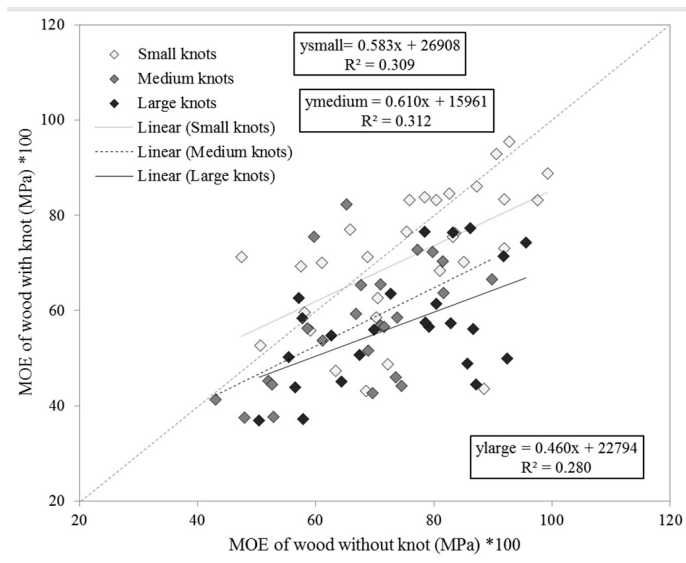

Figure 4. Two-dimensional plot of the clear wood MOE values versus the MOE values of the knotted wood within the three size classes.

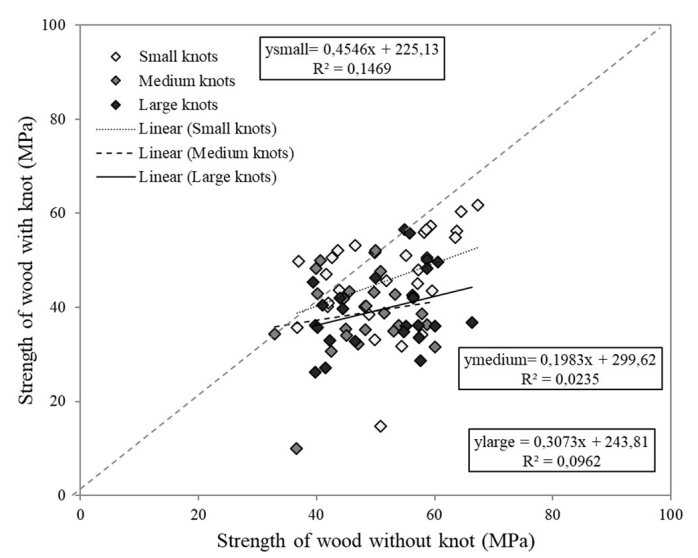

Figure 5. Two-dimensional plot of the clear wood strength values versus the strength values of the knotted wood over three size classes. 
It was observed that the models estimated for the different knot classes presented low coefficients of determination, similar to those observed for the MOE. The mechanical strength during compression parallel to the fibers presented a tendency for reduction in the precision of the models with the increase of the area of the knot.

In the region of the knots, the orientation of the wood cells in the branch follows a different orientation to the wood cells of the trunk, resulting in the reduction of diverse mechanical properties of the wood such as resistance to parallel and perpendicular compression the fibers, and traction and flexion (Green et al. 1999). There are also variations in other properties such as basic density, irregularities in the rings, occurrence of decomposing fungi, higher deposition of extractable components and discontinuities between the node and the surrounding wood, joint action or isolated from these factors contributes to the reduction of the mechanical resistance of the wood in the region of occurrence of a node (Vital, 2008; Fiorelli et al., 2009; Koman et al., 2013).

There is, indeed, a relationship between the knot dimensions and the parallel compressive strength of the wood fibers. According to Koman et al. (2013), the knot size has an inverse effect on the mechanical strength of the wood such that the increase in the knot area results in a significant reduction of both the modulus of elasticity and the mechanical strength of wood.

\section{CONCLUSION}

The effect of the knots on the mechanical properties of the wood depends on the dimensions occupied by these defects in the wood, such that the size of the area occupied by the knot presents an inverse relationship to the wood mechanical properties.

\section{ACKNOWLEDGEMENTS}

The author expresses special thanks to the Wood Science and Technology Laboratory of the Universidade Federal de Lavras (UFLA, Brazil) for supporting the experimental work. This study was funded by $\mathrm{CNPq}$ (National Council for Scientific and Technological Development, Brazil), CAPES (Higher Education Personnel Improvement Coordination, Brazil), and
FAPEMIG (Foundation for Research Support of the State of Minas Gerais), Brazil.

\section{SUBMISSION STATUS}

Received: 31 oct., 2017

Accepted: 07 nov., 2017

\section{CORRESPONDENCE TO}

\section{Maria Fernanda Vieira Rocha}

Departamento de Ciências Florestais, Universidade Federal de Lavras - UFLA, Rua Camélia, 326, Sagrada Família, CEP 39401-020, Montes Claros, MG, Brasil

e-mail:mfvrocha@yahoo.com.br

\section{REFERENCES}

American Society for Testing and Materials - ASTM. Annual book of ASTM standards. Denvers, (D 143-94 - Standard methods of testing small, clear specimens of timber). Philadelphia: ASTM; 1997, p.23-53.

Burger ML, Richter HG. Anatomy of wood. São Paulo: Nobel; 1991. 154 p.

Fiorelli J, Dias AA, Coiado B. Mechanical properties of structural pieces of Pinus spp: relationship between tensile strength and visual grading. Revista Árvore 2009; 33(4): 741-750.

Grant DJ, Anton A, Lind P. Bending strength, stiffness, and stress-grade of structural Pinus radiate: Effect of knots and timber density. New Zealand Journal of Forestry Science 1984; 14(3): 331-348.

Green DW, Winandy JE, Kretschmann DE. Mechanical properties of wood, Madison: Department of Agriculture, Forest Service, Forest Products Laboratory; 1999. Chapter 4, Wood handbook, p. 76-120. (FPL-GTR-113. U.S.)

Gupta R, Basta C, Kent MS. Effect of knots on longitudinal shear strength of Douglas-fir using shear blocks. Forest Products Journal 2004; 54(11): 77-83.

Hossein MA, Shahverdi M, Roohnia M. The effect of wood knot as a defect on Modulus of Elasticity (MOE) and damping correlation. Notulae Scientia Biologicae 2011; 3(3): 145-149. http://dx.doi.org/10.15835/nsb336119.

Koman S, Feher S, Abraham J, Taschner R. Effect of knots on the bending strength and the modulus of elasticity of wood. Wood Research 2013; 58(4): 617-626.

Košíková B. Morphological and chemical characteristics of stem and knot poplar wood. Wood Research 2009; 54(3): 117-122. 
Krutul D, Zielenkiewicz T, Zawadzki J, Radomski A, Antczak A, Drożdżek M. Influence of knots on the content of chemical substances in knot adjacent oak wood (Quercus petraea Liebl.) Ann. WULS - SGGW. Forestry and Wood Technology 2013; 83(1): 112-123.

Nagai H, Murata K, Nakano T. Strain analysis of lumber containing a knot during tensile failure. Journal of Wood Science 2010; 57(1): 114-118.

Oh JK, Kim KM, Lee JJ. Use of adjacent knot data in predicting bending strength of dimension lumber by X-ray. Wood and Fiber Science 2010; 42(1): 10-20.

Vek V, Oven P, Ters T, Poljanšek I, Hinterstoisser B. Extractives of mechanically wounded wood and knots in beech. Holzforschung 2014; 68(5): 529-539. http://dx.doi. org/10.1515/hf-2013-0003.

Vital BR. Planning and operation of sawmills. Viçosa: UFV; 2008. 211 p.

$\mathrm{Xu}$ P. Estimating the influence of knots on the local longitudinal stiffness in radiata pine structural timber. Wood Science and Technology Journal 2002; 36(6): 501-509. http://dx.doi.org/10.1007/s00226-002-0156-2.

Zhou Z, Yin J, Zhou S, Zhou H, Zhang Y. Detection of knot defects on coniferous wood surface using near infrared spectroscopy and chemometrics. BioResources 2016; 11(4): 9533-9546. http://dx.doi.org/10.15376/ biores.11.4.9533-9546. 